\title{
Amalia $X$ : dialogical sequence analysis as a method in theory-based single case research in psychoanalysis
}

\section{Kivikkokangas, Sami}

2018

Kivikkokangas, S \& Leiman , M 2018 , ' Amalia X: dialogical sequence analysis as a method in theory-based single case research in psychoanalysis ', Scandinavian Psychoanalytic Review , vol. 41 , no. 2 , pp. 108-118 . https://doi.org/10.1080/01062301.2019.1597447

http://hdl.handle.net/10138/313938

https://doi.org/10.1080/01062301.2019.1597447

acceptedVersion

Downloaded from Helda, University of Helsinki institutional repository.

This is an electronic reprint of the original article.

This reprint may differ from the original in pagination and typographic detail.

Please cite the original version. 
Sami Kivikkokangas ${ }^{\mathrm{a} *}$ and Mikael Leiman ${ }^{\mathrm{b}}$

${ }^{a}$ Department of Medicine, University of Helsinki, Helsinki, Finland; ${ }^{b}$ Department of Psychology, University of Eastern Finland, Joensuu, Finland

Corresponding author contact details:

Sami Kivikkokangas

Oskelantie 5 C 23, 00320, Helsinki

sami.kivikkokangas@protonmail.com,phone +358406477130

Notes on contributors

Sami Kivikkokangas is a special psychologist, psychodynamic adolescent psychotherapist, supervising and training psychotherapist in integrative psychotherapy, who works as a clinician in public sector and in private practice. As a researcher, he prepares his thesis focusing on change process research in psychoanalysis at the Clinical Research Doctoral School at the University of Helsinki.

Mikael Leiman, $\mathrm{PhD}$ is Professor Emeritus of the University of Eastern Finland. He is the founder and developer of Dialogical Sequence analysis. The first version of the tool was published in 1997 and the current version finalised in 2013 after intensive R\&D work in counselling with marginalised youth. The next setting to test the tool was at the psychiatric outpatient clinics in Lahti and Kuopio areas in Finland. A randomized clinical study, comparing standard psychiatric assessment and the DSA, was conducted at the clinic in Lahti and is currently being published. 


\section{Amalia X - Dialogical sequence analysis as a method in theory-based single case research in psychoanalysis}

In this article Dialogical sequence analysis (DSA; Leiman, 2004, 2012) is introduced as a method in theory-based single case research. The structure of article is as follows: first, we will describe briefly the historical background of single case studies and their position as the foundation of psychoanalytic knowledge formation. Secondly, we will describe through Amalia X's case (Kächele et al., 2006; Thoma \& Kächele, 1994a, 1994b, 2007; Dahl, Kächele \& Thoma, 1988) how one psychoanalytic 'specimen case' has been used as a cornerstone for a comprehensive psychoanalytic process research model, the so called 'Ulm model' (Kächele et al., 2006). Amalia $X$ is one of the most studied single cases internationally also outside psychoanalytic process study field. Thirdly, we will introduce the central theory and practice of DSA. Fourthly, in the last section of our article, we will show in practice how DSA can be used in the analysis of Amalia's dream in the session 152.

Keywords: dialogical sequence analysis; microanalytic methods; single case research; change process research; vulnerability

\section{Introduction}

The familiar result from psychotherapy efficacy studies is that, regardless of the specific psychotherapy orientation or the methods used, different models of treatment are equally effective (Wampold, 2015). The paradox of equal outcomes and differing techniques (Stiles, Shapiro, and Elliott, 1986; Elliott, Barker, \& Hunsley, 2015) calls for a shift toward process studies, that is, to investigate in more detail how different therapies approach clients' predicament and what are the means by which the therapists address the problem.

All psychotherapies depend on the client's expression. Clients vary greatly in their ways of disclosing their problems, their habits of approaching personally difficult issues, and their abilities to reflect on their internal states. The individual variation is immense, and utterances form the only channel by which client experience is communicated.

Psychotherapies differ in the ways by which therapists address client expression and what they are supposed to do with it. Some therapies are client centered while others are mainly therapist driven. Depending on how the therapists meet their clients' 
communication, psychotherapies may be arranged on a continuum. Psychoanalysis allows maximum freedom of expression, whereas cognitive and behavioral therapies shape and direct client expression according to the therapist's technical orientation.

Nevertheless, irrespective of their model, therapists must make sense of what their clients are communicating. They convey their understanding by formulations, using the conceptual perpectives of their model and perhaps suggesting some specific technique to explore the client's experience in more detail. If necessary, clients can correct and enhance therapist understanding through their responses to the therapist's proposals.

Clinical experience shows that psychotherapy is a developmental process. Even if the variation is vast, there are some generalities that seem to apply to all successful therapies. Freud's famous formulation "Where id was, there ego shall be" captures one fundamental feature. During the process, the client is gradually able to access disavowed experiences or forbidden wishes and work out another way of relating to them.

From a psychoanalytical point of view, the aim of identifying and understanding this fundamental change process has been described under the term curative factors. In Finnish psychoanalytical thinking, two different approaches to addressing curative factors can be identified. The developmental paradigm (Tähkä, 1993) conceptualizes the central aim of the analytic process and the interventions of the analyst to help the analysands overcome their developmental arrest. The other approach emphasizes the development of the analysands' self-observation as the central curative element (Ikonen, 2004, 2002; Leiman, 2012).

There are good reasons to argue that, for some clients, the developmental approach may be most appropriate while for others, focusing on client self-observation and its impediments will be enough. One task of psychotherapy change process research is to show how each approach operates and how it affects the communicative dynamics between clients and analysts.

Psychotherapy is indeed a living laboratory in which to study clients' experiences and mental content through their utterances. Whereas the therapists can depend on the 
clients' direct verbal or nonverbal feedback on their formulations, researchers cannot test their hypotheses in this way. Client-therapist interaction is fixed in the recordings. The researcher can only generate an outsider view, or a third-person perspective on the material. This is a fundamental limitation of psychotherapy process research that aims at understanding how psychotherapy works.

Recorded client and therapist utterances form the empirical data for research. To understand how psychotherapists receive client talk and what aspects of its content they address by their responses, a conceptualization of the utterance that relates its content to its dynamic, interactive, and sequential structure is needed.

The situation that prevails in psychotherapy process studies is paradoxical in the sense that most research methods abstract the content of client utterances from analysis. This is done in order to extract generalizations across a client group. Addressing formal aspects of communicative interaction typifies all quantitative process research. Retaining the unique content and flow of client talk is impossible in a research paradigm that aims at finding general variables that might account for therapeutic outcomes regardless of the persons involved in the task.

Alternatively, when the content of client utterances is considered, it is predetermined by the unit of analysis, which only focuses the analysis on selected aspects of client utterances. Classical examples of this approach are Core Conflictual Relationship Theme, or CCRT (Luborsky \& Crits-Christoph, 2003) and Structural Analysis of Social Behavior, or SASB (Benjamin, 1974; 2003). CCRT, for instance, identifies sequences of wish, response from another, and response from the self. Relational conflicts and dilemmas are indeed salient contents of problematic experience. However, only focusing on interpersonal issues leaves out vast areas of the client's internal life and relations with self. SASB does allow the analysis of self-to-self relationships, but formalizes them in the eight predetermined categories in the circumplex (self-affirm, self-blame, self-neglect, etc.).

In summary, there are two main problems in addressing the infinitely varying content of client discourse that characterize current process research methods: The first problem has to do with the pre-ordered arrangement of the material. If - as in CCRT or SSAB - 
the unit of analysis determines what aspects of the client's utterances are considered, then potentially meaningful parts are left out. The second problem is the abstraction of content of client utterances into formal categories. Grounded theory (Glaser \& Strauss, 1967) represents a classical approach to such categorization. Conversation analysis (CA) is increasingly being used as a microanalytic method to study therapeutic interaction. Although excellent in identifying and showing the actual practices through which change happens in clinical situations (Sidnell, 2012, p. 78; Peräkylä et al., 2008), CA focuses on the sequential organization of utterances by formalizing the content of client discourse into categories such as complaint stories, subjective emotional expressions, etc., but does not focus on how the personal content in client utterances affect the dynamics of interaction.

The methodological constraints of current mainstream process methods fail to bridge the gap between systematic research and clinical case descriptions. This explains why only a small percentage of practicing psychotherapists find process studies interesting. They feel that something more is needed in order to describe how clients bring their individual life experience, or internal world, into the sequential and dynamic interaction of psychotherapy and how this content affects its course.

In this article, we will introduce "Dialogical Sequence Analysis" - "DSA" (Leiman, $2012,2004,2002)$, which is a microanalytic method with which to study client and therapist utterances. DSA was originally developed in the context of psychotherapy supervision to articulate how repetitive patterns of mental action sequences could be identified in client utterances (Leiman, 1997). More recently, DSA has been applied in microanalytic studies of psychotherapy (Leiman \& Stiles, 2001; Leiman, 2002; 2004; 2012; Stiles \& al., 2006; Zonzi \& al., 2013; Tikkanen, 2015; Valkonen, 2018). Next, we will describe the basic concepts and the unit of analysis of DSA, used as tools of analyzing client and therapist utterances.

\section{Dialogical sequence analysis}

The fundamental conception of DSA is that all action - including psychic action - is object directed. This view goes back to the views of Franz Brentano. Freud integrated 
Brentano's idea while investigating the object directness of desiring. Desire gives objects valence: they appear to a person as inviting, rejecting or disinterested.

The British object relationship school developed the theory of internal objects. Melanie Klein conceived of internal objects as constituted by unconscious fantasies that are the psychic representatives of life and death instincts. She emphasized that internal objects have similar dynamic power as do the external objects of desire.

In DSA, fantasies, memories and representations are regarded as internal objects to which we always adopt a personal stance, just as we do with external objects. This stance is expressed by the emotional tone that colors any description of our mental content. The basic unit of analysis in DSA is "stance to object".

It was originally Mihail Bakhtin who formulated this unit of analysis in order to examine utterances:

... logical and semantically referential relationships [i.e. language and words that refer to objects] must be embodied, or personified, that is, they must enter another sphere of being: they must become words, that is, utterances, and receive an author, a creator of the utterance whose position they convey. (Bakhtin, 1984, p. 184).

Utterances express the speaker's position regarding the referential object. When we speak about something, we invariably communicate our personal relationship to that object, be it another person, an aspect of ourselves, an event in the world, a dream, a memory, a personally meaningful idea, or the everyday things that surround us. (Leiman, 2011).

The basic assumption in DSA is that utterances express our personal stance to the referential objects, whatever they might be. Bahtin also formulated another principle that characterizes utterances. They are always aimed at a recipient. Even a private internal chain of thought is addressed to an internal other whose response the person anticipates. "About what" and "to whom" are tightly related (Leiman, 2012). We do not disclose our intimate thoughts to just anybody, and we anticipate the response from the 
other largely through our personal stance to the referential object of which we intend to speak.

Transference is a prime example of this two-sided relationship between content and recipient. It is no wonder that Freud first identified transference as resistance, as it interrupted the patient's free association. The patient could not approach some mental content because the anticipated response by the analyst interfered.

\section{Signs as referential networks}

DSA is based on a specific understanding of signs as the primary mediators both of mental processes and communication. This conception is presented in more detail in a paper that discusses Bakhtin's contribution to psychotherapy research (Leiman, 2011).

Briefly stated, signs are born as traces of encounters. Once formed, they begin to mediate all subsequent actions, both mental processes and actions directed to external objects. There are two sign systems. The first we share with the animal world, and which we usually call sensations. The second sign system is born in social interaction and communication, words being the prime example.

There are complex developmental relationships between these two mediatory systems, but both share the basic structure as traces of encounters. Signs refer to the encounter between the acting subject and the object in two ways. First, the trace signifies the object and this aspect is called "object reference". Secondly, the reciprocal event of encountering the object generates a set of referential relations, called "relational reference". Any sign contains in its meaning both kinds of references. Hence, our traditional understanding of "meaning" can be seen as a referential network.

This understanding of semiotic mediation is quite different from the standard understanding of cognitions as representations. Instead of forming a "picture" of our external world, we perceive it according to the referential networks that are embedded in our internalized signs. Moreover, emotions and feelings are understood as the relational references in the sign's network. Normally, everything in our external and internal world has a feeling or an emotional coloring. If this is missing, there is a 
dissociation. Freud's early observation of a missing feeling component (1894) is an illustration of such dissociations that traumatic encounters with objects may generate.

This conception of signs is important for DSA, because words that we use to express our experiences in psychotherapy also contain this double reference. Every word has a potentially unlimited network of personal meanings, and the choice of words by which the patients express their personal experience is affected by these private networks. As researchers, we only perceive a limited sample of these embedded networks and must avoid augmenting the gaps of our understanding by imposing of our own generalizations or speculations.

This conception of signs is fully aligned with Freud's understanding of free association of the paramount method to study mental processes. The patient is instructed to observe whatever is going on in the mind and expressing it verbally to the analyst. External words refer to internal events in one way of other. In the beginning, the analyst does not yet understand the complex referential relationships that are embedded. Hence, the analyst's attitude of evenly distributed attention is the best way to approach the patient's network of references. Sooner or later the patient's free association is stopped by a rift or gap in the network, and the analyst's help is then needed (Ikonen, 2004)

\section{Dialogical sequence analysis - how it is used?}

DSA is a method for systematic case studies. The way DSA is used depends on the research question. It adapts to different kinds of research question. For example, DSA can be used to produce a formulation of the patient's problematic sequences of action via the microanalysis of the first session. Different types of research questions can focus on different aspects of the therapeutic process: What is the nature of patient's problematic experience and what kind of thematic contents belong to it? What kind of obstacles are there in patient's self-observation? Through what kind of interaction is a new kind of relation toward problematic experience enabled? Formulation can be used as a tool that makes it possible to follow how the patients problematic experience gradually comes within the grasp of his self-observation and how his relation changes toward the referential objects of the problematic experience (Leiman \& Stiles, 2001). 
Formulation can also be used to assess to accuracy of therapist's action and the correctness of their timing in the therapeutic interaction (Stiles et al., 2006, Zonzi et al., 2013).

In psychotherapy research DSA is done in a data-session group (Tikkanen, 2015; Kivikkokangas, 2017). By definition the group consist typically of 3-5 clinicians and researchers who are familiar with the basic concepts of DSA. This requires knowledge on the central ideas of action theory (Vygotsky, 1978), Bahtin's theory of utterance (Bahtin, 1984, 1991) and the writings of Mikael Leiman (1997, 2002, 2004, 2012). Familiarity with the conceptual content of psychoanalysis is of substantial benefit, because its close relationship to the theory of utterance is so obvious.

Before the researcher bring the clinical material to the data-session group, he or she familiarizes him- or herself with the audiotapes and the transcripts ("immersion into the data', McLeod, 2010). Because the thematic and meanings of the referential objects of the patients and the therapist's expression develop and relate to each other during the course of therapy, the first step for the researcher is to acquire large amounts of clinical data. The specific research question determines what the researchers chooses to bring to the joint investigation in the data session group. For example: 'what is the repetitive pattern in the material?' or 'how does the subject relate herself to the problematic experience?' DSA is a way of reading the material, and depending on the research question, it directs how it is read.

The task of the data-session group is to identify the referential objects of utterances and the speaker's relations to these, while at the same time keeping in mind that the utterance is always addressed to the addressee. This can be done in different ways. Valkonen (2018) used as an example a procedure, where each of the data session members made an individual-DSA of the material and then compared these to the others for reliability. Each of the members were to identify from the selected transcripts all the referential objects, the suggested relationships toward the referential object, and clarify the passage in transcripts from which material this decision was made. Another method, following Leiman (personal communication, 2018), is 'the painting technique'. In this technique, different colors are used to distinguish the subject's different positions to referential objects, where the shifts in the referential object are easily identifiable from 
the material. In this paper, we have aimed to introduce yet another way to do this. The problem in these different types of annotations is that the boundaries of semantic positions are not always clear cut in utterances. The subtleties and multi-layeredness require analysis made in a group. Each member of the group resonates in different ways to the content of utterances and identifies different shades in the network of referential objects.

The aim of the analysis is almost the direct opposite to the research tradition that highlights the similarity of observations as the basis of analysis. Instead of reliability analysis, the aim is to bring to the fore the multitude of different subtleties of utterance as richly as possible. That is why the countertransferences and associations of the group members are used maximally in the first phase of analysis. It is only after this stage that the data-session group aims for a consensus in the formulation of the referential objects and relations to the referent from the utterances. Based on the researcher's research question the data-session group chooses the vignettes for the final literal work.

(Tikkanen, 2015, p. 18; Leiman, 2012).

\section{Amalia $X$ and the Ulm's process research model}

Amalia X refers to a German psychoanalytic 'specimen case', which is one of the most intensively studied cases in psychoanalysis and psychotherapy. Her treatment consists of 517 tape recorded sessions. According to a list of research compiled in 2010, there were 72 systematic case studies on Amalia X.

This Ulm's process research model is based on collecting and using systematic single case studies in knowledge formation, where the primary data is open to all researchers. These cases, like Amalia X, are called 'specimen cases' (Dahl et al., 1988). 'Specimen case' refers here to a 'case clearly defined as analytic and the data should be recorded, transcribed and indexed so as to maximize accessibility and visibility' (Luborsky \& Spence, 1971, p. 426). In this way, the aim is to find ways to describe and collect systematically the different dimensions of the psychoanalytic process in a way that would make it possible to use the clinical descriptive data to address different research questions and testing of hypothesis (Wallerstein \& Sampson, 1971; Kächele et al., 2006). 
Despite the limitations, the openness and precision of primary data brings its own useful sides to understand psychoanalytic processes. It creates a way to see and listen to what it is that happens in psychoanalyses. The primary data also facilitates the interplay and co-operation of multiple methodological approaches in understanding change processes in psychoanalysis. In addition, the core idea of having a specimen case is of course not only to test hypothesis for a single case, but also to test the fruitfulness of research methods for improving our clinical understanding (Kächele, 2017). The plea is for moving "from arguing about the therapeutic action of psychoanalysis" to “demonstrating and refining it" (Gabbard \& Westen, 2003, p. 338)

Amalia's psychoanalysis is a prime example of an intensive single case study to which multiple methods are applied. Kächele et al. (2006) structured the vast empirical literature on Amalia to four different levels of observation in the following way: Firstly, clinical case studies have described in the traditional 'case study format' how for example Amalia's self-observation develops through identifying to the analyst's analytic function (Thoma \& Kächele, 1992). The second level of observation is constituted by systematical clinical case studies, where for example transferences from the whole therapy have been studied using structured methods (Thoma, 1982). Thirdly, guided clinical judgements studies assess complex clinical questions using the expertise of experienced psychoanalysts. Fourthly, lingvistic and computer assisted text-analyses provide easy and economic ways to asses for example the typical language used by the analyst or the patient in different phases of the treatment (Kächele et al., 1999)

In the literature on Amalia's case the session 152 is identified clinically (Jimenez, 2004; Akhtar, 2007) as well empirically (Albani et al., 2012; Kächele et al., 2006) as an excellent example of psychoanalytic process and technique. Previously Buchholz, Spiekermann \& Kächele (2015) have used conversation analysis (Peräkylä, 2008) to show, how during the sessions 152 Amalia is able to change her position from being passive object of research, into subject of research that actively brings the discussion forward. In the recent years (Albani et al., 2012; Buchholz, Spiekermann \& Kächele, 2015 ) the need for more microanalytic research to asses and describe the change processes in detail have showed in a more detailed way how and through what kind of interaction this was facilitated. 
The dream as the problematic experience in Amalia's session 152 -example of use the of DSA

Amalia was a 35-year-old teacher when she started her psychoanalysis. The central reasons for seeking help were difficulties in self-esteem and depression. She suffered from hirsutism, that refers to excessive growth of hair all over body. Amalia felt stigmatized by this, and inhibited to form close sexual relations, although she generally could hide her stigma from others (Kächele et al., 2006). Amalia's life story has been previously documented in detail elsewhere (Levy, Ablon \& Kächele, 2012; Kächele, Schachter \& Thoma, 2008; Kächele et al., 2006; Thoma \& Kächele, 1994).

In the next section we will show in practice how DSA is used through the dream Amalia tells in the beginning of the session 152. The aim of the analysis of Amalia's dream is to produce a formulation of her problematic experience that can be used as a sounding board for later studying of interaction, or it can serve as an individual measure of change in psychotherapy.

In the analysis of Amalia's dream, our aim is to show how the conceptual tools of DSA work as a way of reading the material. Therefore, the emphasis here is on the method section, where the analysis of the dream serves as an illustration. In order to understand the dream, we would need to know more about the referential network of signs that constitute the problematic experience for Amalia (see Kivikkokangas, Leiman \& Enckell, manuscript in preparation). Not much could be said without this kind of contextual information. The argumentation would lie on a weak basis and relay on third party interpretations of the subject's intentions, which is not typical for microanalytic methods studying utterances. Therefore, we have limited our interpretations more to the manifest salient semantic positions in the material.

In order to illuminate the unit of analysis, we have bolded the referent of the utterance, and underlined our hypothesis about the relationship to the referent. One limitation to identifying the relation to the referent here is the lack of knowledge of Amalia's nonverbal communication, although it was accessible for the data-session group. This type of annotation is problematic also because the boundaries of semantic position are 
not straightforward in utterances. The annotations here are at best thought of as guidance. The numbers in brackets refer to the length of the pause in seconds. Micropauses are marked with a dot.

Vignette 1 (session 152, lines $44-63)$

44 P:.hhhhhh (7) ${ }^{\circ}$ Ich habe heut nacht geträumt heut morgen (2) ..hhhhhh (7) ${ }^{\circ}$ last night I had a dream towards the morning (2)

45 hat grad der Wecker (1) geschellt

(1) the alarm had just gone off

$46(1,4)$ ich sei ermordet worden ${ }^{\circ}$ vom Dolch

$(1,4)$ I was murdered with a dagger

$47 \quad \mathrm{~T}:{ }^{\circ} \mathrm{hm}^{\circ}$

P: und zwar war es aber $(0,7){ }^{\circ}$ wie im Film

But it was $(0,7)^{\circ}$ like in a film

$48 \quad(2,2)$ ich musste ganz lang liegen (..) aufm Bauch und hatte den Dolch im Rücken und

\section{$(2,2)$ I had to lie straight quite long (..) on my tummy and I had the dagger in my back and}

$49 \quad(2,2)$ dann kamen ganz viele Leute

$(2,2)$ then lots of people came

50 (5) und (2) ich weiß nicht mehr wofür (-) die Hände ganz ruhig halten irgendwie wie tot

(5) and (2) I don't know why anymore (-) keep my hands quite still as if I were dead

$51 \quad \mathrm{~T}:{ }^{\circ} \mathrm{hm}^{\circ}$ 
P: mir war's sehr peinlich dass der Rock so (h)hoch raufgerutscht war (.) hinten (4:04)

To me it was really painful that my skirt had slid up so high (.) from the back (4:04)

$52 \mathrm{~T}:{ }^{\circ} \mathrm{hm}^{\circ}$

P: und dann kam (.) n Kollege (.)

And then came (.) the collegue

53 ga:nz deutlich sichtbar

Very clearly seen

54 aus XY, das war meine allererste Stelle

From $X Y$, that was my very first job

55 (1) der hat mir dann den Dolch aus m Rücken gezogen und mitgenommen ähm

(1) he pulled the dagger out of my back and took it with him erm

$56 \quad$ (.) ich weiß nicht das war wie so'n Souvenir

(.) I don't know it was as if souvenir

$57 \quad$ (2) und dann kam $\mathbf{n}$ junges Paar

(2) and then came a young couple

$58 \quad$ ich weiß nur dass er Neger war

I only know that he was a negro

59 und die haben mir dann die Haar abgeschnitten und wollten daraus tatsächlich ne Perücke glaub ich machen

And then they cut my hair off and wanted to make a wig out of it I think

60 (2) und das fand ich ganz schrecklich

(2) and that i found really dreadful

61 (2) und die ham dann auch angefangen zu schneiden

(2) and then they bagan to also cut

62. (3) und (2) ich bin dann aufgestanden (2) und bin zu nem ((leichtes Lachen)) Friseur

(3) and (2) then I got up (2) and went (light laughter) to the hairdresser

63 (3) ((schluckt)) ich mein da hat dann noch der Wecker (-) ((schluckt)) geschellt

(3) ${ }^{\circ}$ und bin aufgewacht ${ }^{\circ \circ}$

(3) (swallors) I think then had the alarm (-) (swallows) rang (3) ${ }^{\circ}$ and I woke up ${ }^{\circ \circ}$. 
In another paper (Kivikkokangas, Leiman \& Enckell, manuscript in preparation), we have analyzed in more comprehensive way, how Amalia's relation toward this dream as a problematic experience is developed and transformed in the sequence of sessions 152 -156 . The material from the sequence of sessions $152-156$ enables us to understand more fully the referential network of signs, which Amalia's problematic dream experience is linked to. It is not possible to do that from the more sparse material. In the following, we will quote from this paper the beginning of analysis of Amalia's dream:

Amalia's dream can be divided into three thematic scenes. The first sequence begins with a straightforward description." I 'd been murdered with a dagger" (46). Amalia demonstrates her attitude to the event by another descriptive statement, indicating an emotional distance as if being a spectator of a movie (47).

A more detailed description follows (48), that is condensed to the expression" somehow like dead" (50). Amalia's previous words are descriptive 'I had to lie straight quite long // I don't know why // keep my hands still'. Something forces Amalia to immobility, but she can't grasp it. The viewpoint of the description changes between observing and experiencing position. This is manifested in the change of referential object (49) to the people coming by.

Then (51) Amalia changes her position from a spectator to being identified with herself, sensing that her skirt had slipped up. This utterance contains a clear semantic position. The slipping of the skirt 'so high' was 'so embarrassing for me', contains both the referential object and Amalia's attitude toward it. 'Sehr peinlich' is Amalia's first expression of her attitude toward the skirt and the present people. Listening from the audiotape, Amalia's intonation in 'skirt' gives us a more complicated clue of her attitude to the referential object. There she's almost on the break of crying, her voice cracking to silence, but then quickly 'standing up' and getting a hold of herself to complete the utterance. This emotion word is the very first distinct expression of her multilayered attitude to the detailed perception of her skirt.

Another aspect of the dream is the logic of the dream and Amalia's relationship toward the dream. Instead of focusing on the repetitive theme or pattern (the relationship between Amalia and others), we could focus on how Amalia changes her relation to her dream. Depending on what is accessible for Amalia at the moment, she blurs the 
boundary between the dream scene and reality, changes her position between observing and experiencing positions toward the emotional core of the dream event. These aspects of the dream may serve here primarily as examples of different types of alternative research questions. Choosing another research question would then determine in different what material we bring for a focused joint investigation. In this way, DSA is always a way of reading the material depending on the research question.

The next scene describes her colleague, who pulled the dagger out. A straightforward description of the act is interrupted by a comment that identifies the colleague ('I could easily see') and qualifies his act by suggesting his attitude ('took it with him... like a souvenir').

DSA pays attention to the choice of words. The speaker's attitude to the referential object is often embedded in the word meaning. The speakers chosen words also always reflect the influence of the addressee. In studying utterances DSA pays attention to how the speaker always takes the other into account in her expression. What can be said is connected to whom these words are addressed. In addition, the idiosyncratic developmental history of the word is embedded in it as a possibility. Here 'like a souvenir' portrays the colleague's attitude to the dagger that had been stabbed in her back. The dagger and the souvenir contain probably a rich network of meaning for Amalia that can't be seen straight from surface or the literary meaning (or general vocabulary meanings). Amalia had a slight difficulty in finding the right expression, indicated by 'I don't know' and 'it was as if'.

In DSA one must be wary to speculate the symbolism of the dagger or the souvenir. In psychotherapy research, the analysis of the material takes place after the clinical encounter, the patient can't respond to the accurateness of the interpretation. Here Amalia is describing the action of another person, which seems from this perspective straightforward and a non-problematic action in the situation.

The third scene (57-61) contains a similar tension between two positions to one object. Now the referential object is Amalia's hair. The structure of the sequence is almost identical to the scene with the colleague. First, Amalia describes the young couple, followed by a more detailed qualification of the man ('I just know that he was a Negro'). While the colleague transformed the dagger into a souvenir, the couple cut her 
hair and made a wig out of it. This descriptive statement is interrupted by a distinct expression of attitude 'and that seemed really dreadful "(60)), and continued after a two-second pause with the reference to actual cutting of her hair. Also, in this event Amalia is paralyzed and can't do anything to the actions of the others. The others don't seem to have any relation to Amalia's terror.

The dream ends abruptly with an associative reference to the hairdresser. This reverses the temporal order of the mornings events in comparison to the last utterance, the description of waking up ('I think then had the alarm rang (schluckt) and I woke up"). From the alarm clock and waking up, was where Amalia's dream telling also started.

The thematic unity in the dream lies in the tension between the apparently unconcerned or light-hearted attitude of the others (people passing by, the colleague, and the young couple) to matters that were deadly serious for Amalia (dagger, skirt, and her hair). This summary may serve as a DSA-based formulation of Amalia's problematic experience. She seems to be a divested victim of powerful others who can do whatever they like to her. This formulation is based on a sparse summary of the semantic positions in the manifest dream content. In addition to vulnerability, shame is implied to be one of the central semantic position, although it shows itself only in the reference to the skirt 'slipped up so high'. (Kivikkokangas, Leiman \& Enckell, manuscript in preparation)

\section{Discussion}

DSA is a microanalytic method for theory-based single case studies in psychoanalysis. This is its context. DSA is also a method for studying interaction. The speaker always takes into account the addressee. There's no utterance without the other. This is something DSA shares with its close cousin Conversation analysis (Peräkylä, 2008). The main difference of the two methods comes from the notion of emotional stance to referent lacking in CA. This emphasis on interaction is something lacking from the more traditional research methods (one-person psychology), where DSA aims to bring psychoanalysis to this day (two-person psychology).

Why do we need another method? DSA always adapts to the research question. It is a disciplined way of reading the material, where the research question directs the process 
of the study. DSA is a way to operationalize the process of how attempts to understand something psychoanalytic is done. It aims to bring more methodological clarity and transparency to the 'psychoanalytic instrument' we use to gain understanding of the clinical material. It is crucial for psychoanalytic process studies to communicate this information to the wider psychotherapy research field in a way that promotes collaboration and shared effort to understand psychoanalytic change processes. This is of course not only to make the psychoanalytic method communicable outside psychoanalytic journals. It's for the psychoanalysts also. What different dimensions is there to psychoanalytic understanding? When we clarify and discuss about these together, it also focuses or brings into focus the 'psychoanalytic instrument' of understanding.

In this article, the problematic experience that we followed through the short sequence from Amalia's session 152, emerged first in the dream at the beginning of the hour. The formulation of Amalia's problematic experience was made using DSA on the manifest content of Amalia's dreams and the following narration. This formulation is a tool for the researcher. It serves as a starting point that enables for the researcher the analysis of different aspects of the therapeutic process. In the following, we will discuss some of the possible research strategies and question using DSA in Amalia's case.

The research can be delimited only to the analysis of Amalia's progress in the session 152. This is how previous research has approached Amalia's process (Buchholz, Spiekermann \& Kächele, 2015). From this perspective, the focus is on Amalia's ways of relating to her dream and its meanings while the analyst tries to help her in this task. The dream constitutes a jointly created referent to which Amalia and the analyst construct different semantic positions. The analyst's attitude to the referent is mediated through the analyst's theoretical orientation and the formulations used to help Amalia's process. Amalia's dream resides within a referential network of meanings she's unable to grasp immediately. The continued analysis of the hour's contents and dynamics makes it possible to display the connections and tensions between these two attitudes.

If the aim of the research is to show, through what kind of analytic process Amalia is able to become more aware of the meanings of her dream and use these selfanalytically, we need more extensive clinical data. The dream can become a metaphor for carrying the process of 'making conscious the unconscious', and function as a tool 
for joint observation until the end of the treatment. Modern text-recognising tools could be used to identify how it is later used, where microanalysis of these could uncover the enrichment and transformation of the metaphor. The task of the analysis is laborious when there are over 500 sessions in Amalia's analysis.

The research question is central in determining the required extensity of the clinical data. In order to avoid the analysis of hundreds of sessions, the research can be limited to the question: when and through what way Amalia's attitude to the referent (the thematic of her dream) changes, and begins to orient her self-observation. In another paper (Kivikkokangas, Leiman \& Enckell, manuscript in preparation), we showed how Amalia's relation to the problematic referential object of 'being vulnerable and exposed in front of powerful others' changed and developed through multiple phases between the sequence of sessions of 152 - 156. Amalia's attitude toward the referent manifested in the beginning as resistance but then though analytic process begins to give room for more co-operative ways of working. Then, these changes enabled a new kind orientation for her self-observation, where Amalia was able to become more aware of the meanings of her dreams and use these self-analytically.

The DSA formulation based on the contents of the dream (vulnerability, shame) can be used as a tool for analysis, that uncovers the semantic positions first manifested in the dream and later manifesting in relation to other themes in the following sequence of sessions. For example, Amalia might not say anything about vulnerability or shame besides her dream in the session 152. The relationship between being vulnerable and others is reciprocal. This semantic position (being vulnerable in front of powerful others) could then in the following sequence of sessions 152-156 appear in relation to variety of referential objects. For example, in relation to parents, colleagues or to the analyst. Through analytic clarifying of this referential network, it would then become possible to understand how all these concern Amalia's shame.

DSA by means of concepts constructed reading of the material. This can be clarified by comparing DSA to its close relative, thick description. Thick description is a way to achieve external validity (Lincoln \& Cuban, 1985). By describing the phenomena in sufficient detail, it can be assessed, to which extent the conclusion made from this 
material are transferrable to other situations and people. The term thick description was first used by Ryle (1949), and later used by Geertz (1955) in ethnography. It refers to a detailed and rich description of an experience, where the researchers in a clear way shows the object of research in context (Honkasalo, 2008; Holloway, 1997). Thick description is needed in order to interpret the meaning of certain act (for example, a wink of an eye) in certain culture and social relations. This can be compared to thin description, which refers to a superficial account (the wink is just a twitch of the eye) without understanding the meaning of the act in certain context. In parallel to 'thick description' in DSA, also the conclusions and the material the researcher has used as a basis to reach those conclusions, are made available to the reader to criticize.

The central difference between DSA and 'thick description' are the concepts in analysis that mediates the description. In DSA the theoretical concepts are tools that are used to observe and listen to the material. In order to perceive the subject of analysis we need some basic abstractions that determine which relations are meaningful and which are not (Reenkola, 1996). Basic abstraction constitutes a conceptual network, through which the research subject parses into a whole articulating the mutual interconnections embedded in the phenomena. "The image obtained through successful abstraction does not remain abstract in the sense that it would separate the phenomena from its relations. On the contrary, a successful abstraction structures the relations in the phenomenal field and gives a more concrete image from the phenomena via showing to which connections its diverse dimensions belong to" (Reenkola, 1996, p. 86; see Ilyenkov, 1960). In DSA the concepts of action and utterance are these basic abstractions of analysis. The concept of sign is needed in DSA because it is the mediator of utterances.

In DSA theoretical concepts structure perceiving and observation, mediating the way of the description. This can be explained by describing the use of DSA as a method for case formulation. Theoretical concepts structure the clinicians perceiving and observation. The clinicians' descriptions and interventions are based on this understanding. Through this way, this understanding mediates to the progression of the interview and to the jointly created formulation 'what is the problem about' based on this process. Case formulation is the result of this: a concrete description of the patients' actions that seem to maintain the manifest problems. As a description, the case formulation develops accordingly when the therapeutic interaction with the client brings 
new connections and meanings to joint observation. As a way of description, it is central for the case formulation to describe the dynamics of the phenomenal field and events that mediate these. Theoretical concepts constitute in DSA a structured image of the phenomena but are no longer seen from the image that they have created.

\section{Acknowledgements:}

This work was supported by the Finnish Cultural Foundation, Gyllenberg Foundation and The University of Helsinki Funds under the Grant of the first author.

\section{References}

Albani, C., Blaser, G., Jacobs, U., Jones, E., Thomä, H. \& Kächele, H. (2002). Amalia X's psychoanalytic therapy in the light of Jones's psychotherapy process Q-sort. In: Leuzinger-Bohleber M, Target M, editors. Outcomes of psychoanalytic treatments, Perspectives for therapists and researchers. London/Philadelphia: Whurr Publishers; 2002. p. 294-302. 4

Angus, L., Goldman, R. \& Mergenthaler, E. (2008). One case, multiple measures: an intensive case-analytic approach to understanding client change processes in evidencebased, emotion-focused therapy of depression.

Bahtin, M. (1984). Speech genres and other essays. Austin: University of Texas press. Bahtin, M. (1991). Dostojevskin poetiikan ongelmia. Helsinki: Orient Express.

Benjamin, L.S. Structural analysis of social behavior, Psychological Review, 81, 392425).

Benjamin, L.S. (2003). Interpersonal diagnosis and treatment of personality disorders. $2^{\text {nd }}$ Ed. New York, Guilford Press.

Buchholz, M., Spiekermann, J. \& Kächele, H. (2015). Rhythm and Blues - Amalie's 152nd session: From psychoanalysis to conversation and metaphor analysis - and back again. 1, 96 (3) 877-910

Dahl, H., Kächele H, Thoma H, (1988). Psychoanalytic process research strategies. Berlin/Heidelberg/New York/ London/Paris/Tokyo: Springer. 
Elliott, R., (2010). Psychotherapy change process research: realizing the promise. Psychotherapy Research, 20 (2) 123-135.

Elliott, R. (2011). Systematic case study research: A practice-oriented introduction to building an evidence base for counselling and psychotherapy. Counselling and Psychotherapy Research, 11 (1) $1-10$.

Elliott, K.P., Barker, K.K., \& Hunsley, Jo. (2015). Dodo Bird Verdict in Psychotherapy. In Cautin, R.L. \& Lilienfeld, S.O. (Eds.). Encyclopedia of Clinical Psychology. WileyBlackwell. (Retrieved 11.1.2019.

https://onlinelibrary.wiley.com/doi/10.1002/9781118625392.wbecp053)

Freud, s. (1894) Die Abwehr-Neuropsychosen. Gesammelte Werke 1, 59-74.

Gabbard GO, Westen D (2003) Rethinking therapeutic action. Int J Psychoanal 84: 823842

Geertz, C. (1973). The Interpretation of Cultures. New York: Basic Books.

Greenberg, L. (1986). Change process research. Journal of Consulting and Clinical Psychology, 54, 419.

Hohage, R. \& Kübler, J. (1988). The emotional insight rating scale. In: H. Dahl, H. Kächele, H. Thoma, ( editors). Psychoanalytic process research strategies, p. 243-55. Berlin: Springer.

Ikonen, P. (2002). Psykoanalyyttisiä tutkielmia. Helsinki: Nuorisopsykoterapiasäätiö.

Ikonen, P. (2004). Psykoanalyyttisiä tutkielmia II. Helsinki: Nuorisopsykoterapiasäätiö.

Iljenkov, E. (1960). The Dialectics of the Abstract and the Concrete in Marx's Capital. Moscow: Progress Publishers.

Jimenez J., Pokorny, D., Kächele H. (2006). The Psychoanalytic Loss-Separation Model (LSM): Evolution of the reaction to breaks in the psychoanalytic process as an indicator of change. Int J Psychother 10: 22-34.

Holloway, I. (1997). Basic Concepts for Qualitative Research. London: Blackwell Science.

Honkasalo, M. (2008). Etnografia terveyden, sairauden ja terveydenhuollon tutkimuksessa. Sosiaalilääketieteellinen aikakausilehti, 45, 4-17. 
Kivikkokangas, S., Leiman, M. \& Enckell, H. (manuscript in preparation) The development of self-observation as a precondition for self-analytic capacity - the case of Amalia X.

Kivikkokangas, S. (2017). The manifestation and change of shame in psychotherapy (Häpeän ilmentyminen ja muutos psykoterapiassa). Licenciate thesis: University of Jyväskylä.

Kivikkokangas, S. \& Manninen, P. (2017). How does future of psychotherapy look like in 25 years? (Miltä psykoterapian tulevaisuus näyttää 25 vuoden päästä?) Psykoterapia, 36 (3) $227-236$.

Krause, M. (2011). Statistical significance testing and clinical trials. Psychotherapy, 48 (3) $217-222$.

Kächele, H. (2012). Amalia X - the german specimen case. The International Journal of Psychoanalysis 2006: 87, 1-18.

Kächele H, Thoma H, Ruberg W, Grünzig HJ. Audio-recordings of the psychoanalytic dialogue: scientific, clinical and ethical problems. In: H. Dahl, H. Kächele, H. Thoma (editors). Psychoanalytic process research strategies. Berlin: Springer; 1988, 179-194.

Lambert, M. (2011). Solving problems with randomized clinical trials is not enough to improve psychotherapy outcome: comments on Krause. Psychotherapy, 48 (3) 229-230. Leiman, M. \& Stiles, W.B. (2001). Dialogical Sequence Analysis and the Zone of Proximal Development as Conceptual Enhancements to the Assimilation Model: The Case of Jan Revisited. Psychotherapy Research, 11, 311-330.

Leiman, M. (1997). Procedures as dialogical sequences: A revised version of the fundamental concept in Cognitive Analytic Therapy. British Journal of Medical Psychology, 70, 193-207.

Leiman, M. (2002). Toward semiotic dialogism. Theory and Psychology, 12, 221-235.

Leiman, M. (2004). Dialogical Sequence Analysis. In: Hermans \& Dimaggio (edtitors.). The dialogical self in psychotherapy. London: Routledge.

Leiman, M. (2006). What does the first exchange tell? Dialogical sequence analysis and assimilation in very brief therapy. Psychotherapy Research, 16 (4), 408-421.

Leiman, M. (2011). Mikhail Bakhtin's contribution to psychotherapy research. Culture and Psychology, 17(4) 441-461. 
Leiman, M. (2012). Dialogical Sequence Analysis as a method to study psychotherapeutic discourse. International Journal of Dialogical Science, 6, 123-147. Leiman, M. (2018) Personal communication, Helsinki, Finland.

Levy, R., Ablon, J. \& Kächele, H. (2012). Psychodynamic process research. London: Humana Press.

Lincoln, Y. \& Guba, E. (1985). Naturalistic inquiry. Newbury Park, CA: Sage Publications.

Luborsky L, Spence D (1971) Quantitative research on psychoanalytic therapy. Luborsky, L. \& Crits-Christoph, P. (2003). Understanding transference. $2^{\text {nd }}$ Ed. Washington, DC, American Psychological Association.

In: Bergin AE, Garfield SL (Eds) Handbook of psychotherapy and behavior change. Wiley, New York, pp 408--438

McLeod, J. (2010). Case study research in counseling and psychotherapy. London: Sage.

Ryle, G. (1949). The Concept of Mind. London: Hutchinson.

Peräkylä, A., Antaki, C., Vehviläinen, S. \& Leudar, I. (2008). Conversation Analysis and Psychotherapy. Cambridge: Cambridge University Press.

Reenkola, T. (1996). Freudin metapsykologia ja psykoanalyyttinen tiedonmuodostus. In E. Roos, V. Manninen, V. \& J. Välimäki (toim.) Kohti piilotajuntaa. Psykoanalyyttisia tutkielmia, 77 - 120. Helsinki: Yliopistopaino.

Stiles, W.B, Shapiro, D.A., \& Elliott, R. (1986). Are all psychotherapies Equivalent? American Psychologist 41(2):165-80. DOI: 10.1037/0003-066X.41.2.165

Thoma, H., Mergenthaler, E., Kächele, H. (1982). The Topic-Index method for systematic processdescription. Unpublished manuscript.

Thoma, H., Kächele, H. (1994a). Psychoanalytic practice. Vol. 1: Principles. New Jersey: Jason Aronson Inc.

Thoma, H., Kächele, H. (1994). Psychoanalytic practice. Vol. 2: Clinical studies. New Jersey: Jason Aronson Inc.

Thoma, H. \& Kächele, H. (2007). Comparative psychoanalysis on the basis of a new form of treatment report: the case Amalia X. Psychoanal Inq., 27, 650-89.

Tikkanen, S. (2015). The development of empathic stance. University of Eastern Finland. Doctoral thesis.

Tähkä, V. (1993). Mind and its treatment. Madison: International universities press. 
Vygotsky, L. (1978). Mind in Society. The Development of Higher Psychological Processes. Campbridge, MA: Harvard University Press.

Zonzi, A., Barkham, M., Hardy, G.E., Llewelyn, S.P., Stiles, W.B. \& Leiman, M. (2014). Zone of proximal development as an ability to play in psychotherapy with adults. Psychology \& Psychotherapy, 87, 447-464.

Wallerstein, R. \& Sampson, H. (1971). Issues in research in the psychoanalytic process. International Journal of Psychoanalysis, 52:11-50.

Wampold, B. (2015). How important are the common factors in psychotherapy: an update. World Psychiatry, 14 (3), 270-277. 